\title{
KONFIGURASI SERPENTINE-PARALEL DAN PARALEL-SERPENTINE PADA PIPA FLUIDA PEMANAS AIR SURYA SISTEM THERMOSIPHON
}

\author{
Rustan Hatib \\ Jurusan Teknik Mesin, Fakultas Teknik Universitas Tadulako Palu \\ Jl. Soekarno-Hatta Km. 9 Tondo, Palu 94119 \\ E-mail: rustanhatib98@gmail.com
}

\begin{abstract}
The aim of this research is to compare the performance of two differences tube configuration in solar hot water collector thermosiphon system of Serpentine-Parallel and Parallel-Serpentine. Not only the tubes configuration are not the same, but also the collector materials, such as hot water reservoir and heat absorber are differences. For example, fiberglass and stainless steel reservoirs are compared in terms of long-lasting heat isolation. Likewise, copper tubes configuration between serpentine-parallel and parallel-serpentine are shown in association with mass flow rates and times consume to heat the water within the tubes. The test results show that parallel-serpentine configuration has higher performance (around 50\%) than that of serpentine-parallel (approximately 35\%). It is possibly because of fluid velocity within the tube configuration.
\end{abstract}

Keywords: serpentine-parallel, parallel-serpentine, solar hot water, thermosiphon

\section{PENDAHULUAN}

Perkembangan pemanfaatan energi surya dalam kolektor pemanas air mengalami perkembangan signifikan dalam meningkatkan efisiensi dan efektivitas kolektor energi matahari. Salah satu cara yang dilakukan adalah dengan memodifikasi konfigurasi pipa penyerap panas dan bentuk pelat penyerap absorbernya yang di cat hitam. Beberapa penelitian menghasilkan bentuk konfigurasi pipa paralel atau serpentine saja. Padahal masing-masing bentuk tersebut memiliki keunggulan, misalnya konfigurasi pipa paralel cocok digunakan pada sore hari, sementara yang bentuk serpentine atau bentuk seperti susunan usus lebih cocok digunakan pada pagi hingga siang. Oleh karena itu dalam penelitiannya, Mustofa et al. (2013a) dan Mustofa dkk. (2013b) menyatukan 2 konfigurasi itu dalam satu kotak kolektor yang terbuat dari kayu dengan pipa tembaga 1/2" dengan satu dan dua penutup kaca dengan prinsip kerja secara thermosiphon. Hasilnya, panas maksimum yang keluar dari pipa sirkulasi fluida sebelum masuk ke tandon mencapai sekitar $80^{\circ} \mathrm{C}$. Sayangnya panas dalam tandon tidak bertahan lama karena material fiberglass kurang baik kemampuan isolasinya atau resistensi panas. Disamping itu efisiensi kolektor masih perlu ditingkatkan.

Dalam meningkatkan efisiensi dan penampilan kolektor supaya lebih berorientasi pasar, maka dilakukan beberapa modifikasi desain dan material, Mustofa dkk. (2014). Peneliti mengganti material tandon air panas dari fiberglass menjadi stainless steel, bahan kolektor dari kayu diganti menjadi aluminium dan susunan konfigurasi pipa penyerap fluida diubah dari serpentine-paralel menjadi paralelserpentine. Handoyo (2000) dalam penelitiannya yang menguji konfigurasi pipa kolektor pemanas air model serpentine dan paralel secara terpisah menunjukkan bahwa pada pemanasan air energi surya dari pagi hingga siang lebih cocok digunakan konfigurasi serpentine, sementara pada siang hingga sore yang paralel lebih baik dengan temperatur keluar dan efisiensinya yang lebih besar dibandingkan yang serpentine. Ide ini yang mendasari Mustofa dkk., (2014) menggabungkan kedua konfigurasi dalam satu kotak kolektor yang urutan konfigurasinya fleksibel. Artinya bisa dibalik urutan konfigurasinya untuk di uji unjuk kerjanya, seperti pada Gambar 1. 


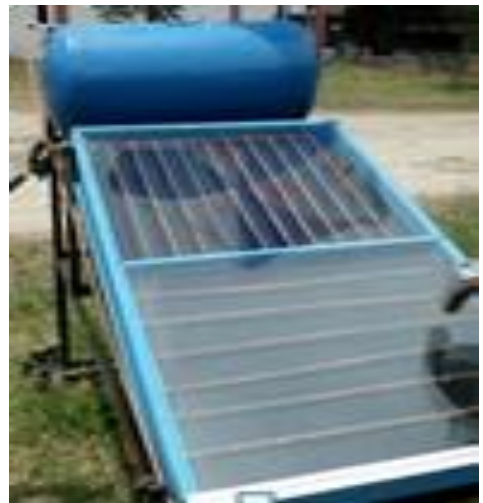

a) Konfigurasi serpentine-paralel

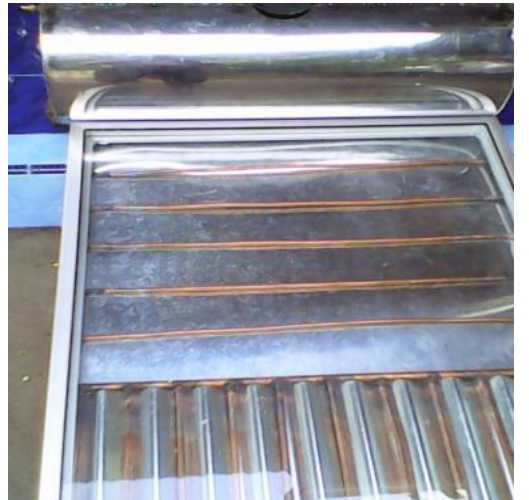

b) Konfigurasi paralel-serpentine

Gambar 1. Prototype Kolektor Pemanas Air

Oleh karena itu, artikel ini mengulas komparasi kedua konfigurasi antara serpentine-paralel dan paralel-serpentine. Secara teori ilmu perpindahan panas, fluida yang dipanaskan dengan energi surya dalam model serpentine mengalami perlambatan aliran yang berimplikasi kepada kenaikan suhu air dibandingkan dengan model paralel. Suhu yang tinggi diperlukan sebelum fluida masuk ke tandon stainless steel untuk memanaskan fluida didalamnya.

\section{METODOLOGI PENELITIAN \\ Pembuatan Alat Paralel-Serpentine}

Dalam pembuatan alat peraga kolektor surya pemanas air digunakan bahan-bahan seperti kotak kolektor dari aluminium, pipa tembaga ukuran 3/8" dan 5/8". Khusus 5/8" dipasang pada header konfigurasi pipa paralel bagian atas dan bawah untuk memudahkan pipa 3/8" masuk ke dalam lubang header untuk selanjutnya di las gas asytelene. Konfigurasi serpentine terpasang pipa ukuran $3 / 8$ " yang langsung masuk ke tandon stainless steel. Tembaga merupakan bahan konduktor yang konduktivitasnya paling tinggi di antara bahan logam lainnya seperti alumunium, kuningan dan besi (Duffie \& Beckman, 2006).

Prosedur awal dalam rekayasa alat ini adalah penyambungan konfigurasi paralel dan serpentine secara terpisah, kemudian pembuatan kotak aluminium dengan susunan paling bawah adalah triplex diikuti sponse setebal $3 \mathrm{~cm}$, pipa penyerap panas dan selanjutnya ditutup dengan kaca setebal $5 \mathrm{~mm}$. Jarak antara pipa penyerap panas dan kaca penutup adalah $3 \mathrm{~cm}$. Ukuran kolektor adalah $123 \times 73 \times 5 \mathrm{~cm}$. Sementara itu tandon air panas dari bahan stainless steel dengan ukuran 80 × $30 \mathrm{~cm}$ dipasang horisontal.

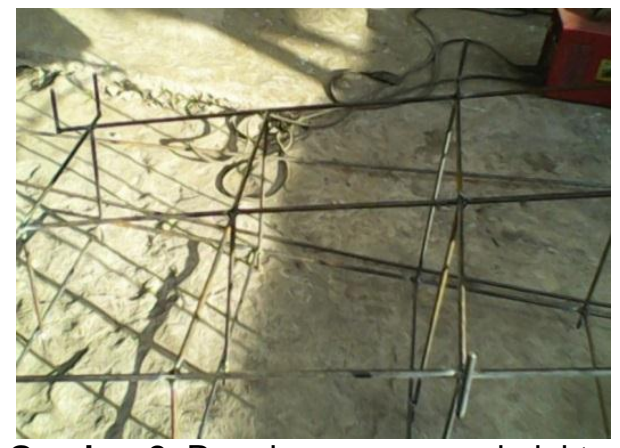

Gambar 2. Rangka penyangga kolektor

Dibandingkan dengan penelitian sebelumnya pada konfigurasi serpentineparalel, bahan tandon dari fiberglass, diameter pipa tembaga digunakan $1 / 2$ " seragam dengan bahan kotak kolektor dari kayu, penelitian kali ini telah mengalami beberapa modifikasi seperti dijelaskan di atas. Setelah kotak kolektor dimodifikasi dan panel kolektor selesai dirakit, selanjutnya dilakukan pengujian.

\section{Prosedur Pengujian}

Panel kolektor dan rangka penyangga yang selesai dirakit kemudian ditempatkan di area terbuka yang mendapat pencahayaan maksimal. Mula-mula suhu air dalam tandon dicatat dengan termometer air raksa yang terpasang di dalam tandon air. Pembacaan suhu dilaksanakan mulai 09.00 sampai dengan 
pukul 15.00 Wita. Percobaan mula-mula pembuatan rangka penyangga kotak kolektor dan tandon stainless steel dibuat dengan menggunakan besi $10 \mathrm{~cm}$. Dudukan panel dibuat miring dengan kemiringan $20^{\circ}$ dari bidang horizontal seperti nampak pada Gambar 2, sementara rangka tandon dibuat tepat di atas panel kolektor dengan posisi lebih tinggi dari kolektor dengan pertimbangan akan memberikan efek termosifon seperti yang terlihat pada Gambar 3. Sisi kiri dan kanan tandon terpasang kran air kuningan yang berfungsi sebagai pembuka dan penutup fluida yang masuk ke kolektor dan masuk kembali ke tandon. Siklus ini berlangsung hingga suhu air dalam tandon maksimum.

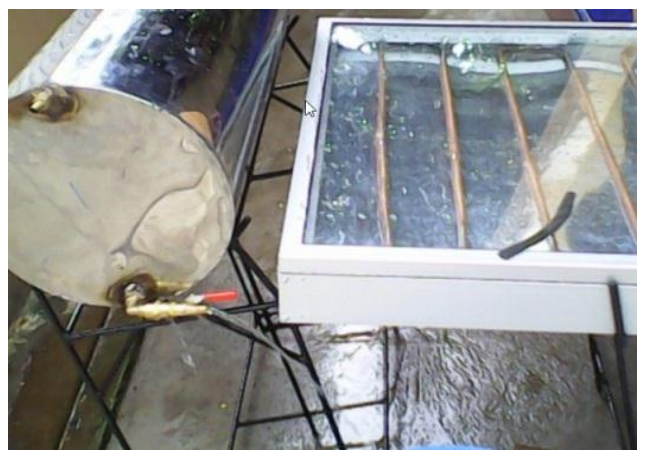

Gambar 3. Rangka penyangga tandon

Pengelasan antara kran kuningan dengan tandon stainless steel dilakukan oleh tenaga profesional dari CV. Junas Nasional Elektronik di Palu yang ahli dalam menservice AC dan peralatan elektronik lainnya. Hal ini dilakukan karena dibutuhkan teknik pengelasan khusus untuk menyatukan kuningan dengan stainless steel. Sayangnya, sambungan kuningan dan stainless steel belum terlalu kuat.

Percobaan dilaksanakan untuk memanaskan tandon air tanpa kolektor surya, sebagai kontrol terhadap kestabilan suhu air tandon di bawah pengaruh radiasi matahari. Percobaan dilaksanakan dengan mengukur suhu air dalam tandon setiap selang waktu 30 menit. Percobaan di atas dilakukan dengan 2 variasi debit aliran, yaitu 0,189 dan $0.035 \mathrm{~kg} / \mathrm{s}$.

\section{HASIL DAN PEMBAHASAN \\ Temperatur Masuk dan Keluar Kolektor}

Pada Gambar 4 terbaca bahwa antara konfigurasi serpentine-paralel dan paralelserpentine hampir tida ada perbedaan, kecuali pada awal-awal pengamatan dengan perbedaan yang agak besar. Hal ini mungkin disebabkan oleh kondisi suhu lingkungan pada hari pengamatan. Suhu stabil terjadi pada tengah hari hingga menjelang sore hari.

Kejadian yang sama terjadi untuk suhu keluar kolektor pada kedua konfigurasi pipa penyerap panas. Hanya saja pada konfigurasi paralelserpentine,suhu air tetap lebih besar dibandingkang dengan yang keluar pada pipa paralel seperti yang ditampilkan pada Gambar5.

\section{Efisiensi Kolektor}

Perbedaan mulai terlihat jelas pada efisiensi kolektor seperti yang ada pada Gambar 6. Kolektor dengan konfigurasi serpentine-paralel berada sekitar 30\%, sementara yang paralel-serpentine pada kisaran 50\%. Hal ini dimungkinkan karena sirkulasi fluida sebelum masuk ke tandon berada konfigurasi serpentine dengan kecepatan fluida yang lebih lambat dengan konduktivitas panas yang lebih besar, sehingga suhunya menjadi lebih besar yang akan memanaskan air dalam tandon stainless steel.

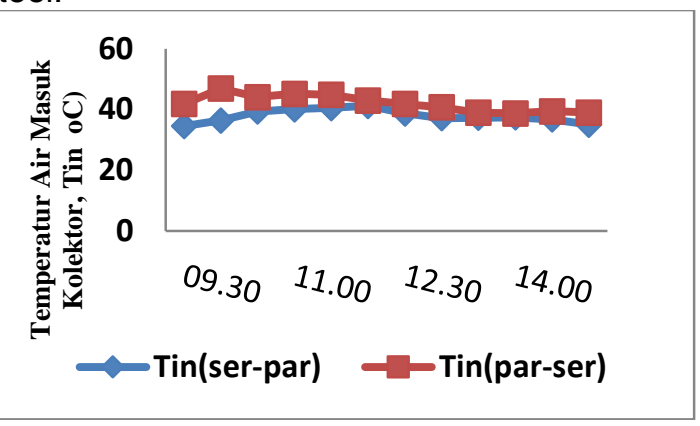

Gambar 4. Suhu air masuk kolektor pada 2 konfigurasi pipa penyerap panas

Dari Gambar 6 juga terlihat hubungan antara efisiensi kolektor dengan waktu pengamatan. Di awal pengamatan hingga sekitar pukul 12.00 kelihatan bahwa nilai efisiensi mengalami ketidakstabilan dengan kisaran yang turun naik pada angka 40 dan $50 \%$ untuk kolektor konfigurasi paralelserpentine dan $20-30 \%$ untuk serpentineparalel. Di atas jam 12.00 hingga menjelang sore jam 15.00, efisiensi kolektor cenderung tetap. Hal ini terjadi karena panas fluida dalam tandon sudah tetap dan tidak ada tambahan 
pemanasan. Artinya sirkulasi pemanasan dalamkolektor tidak banyak berpengaruh pada suhu fluida dalam reservoir. Hanya saja pada jam 14an, terjadi sedikit fluktuasi yang mungkin disebabkan oleh kecepatan angin disekitar kolektor yang berhembus lebih cepat yang berpengaruh terhadap suhu pemanasan

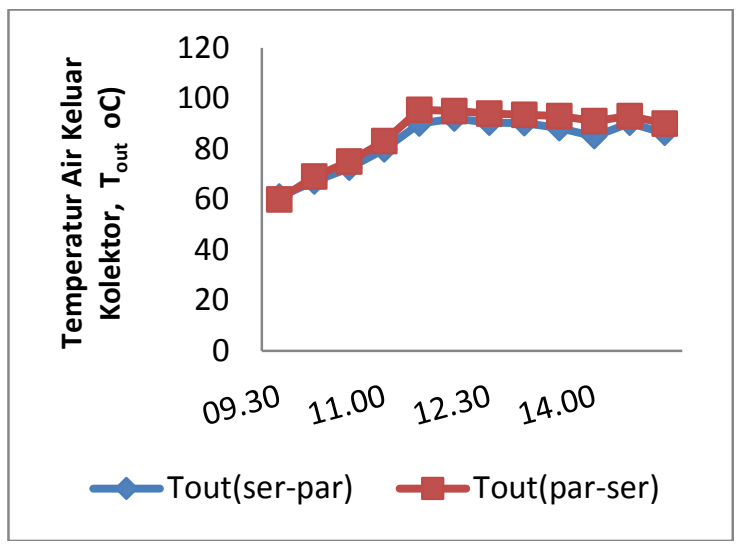

Gambar 5. Suhu air keluar kolektor pada 2 konfigurasi pipa penyerap panas setelah pemanasan

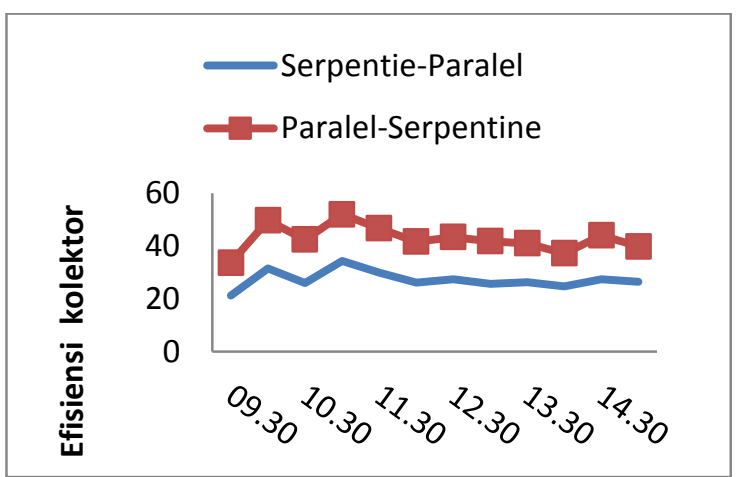

Gambar 6. Efisiensi kolektor serpentine paralel dan paralel serpentine

Sementara itu untuk karakteristik perbedaan temperatur pada desan pipa paralel dan serpentine dimana plat datar terletak di bawah konfigurasi serpentine dan plat gelombang berpasangan dengan konfigurasi paralel, dapat dilihat pada Tabel 1. Hasilnya menunjukkan bahwa delta suhu masuk dan keluar pipa tembaga pada plat datar lebih kecil dibandingkan dengan yang plat gelombang. Hasil pengujian ini juga sejalan dengan hasil penelitian Supriadi (2010). Perbedaanya terletak pada kaca penutup kolektor, yaitu Supriadi menggunakan 2 kaca penutup, sementara penelitian ini hanya satu. Penyebab utama dari fenomena perbedaan delta suhu tersebut adalah luasan plat gelombang lebih besar karena ada lengkungan yang memungkinkan panas yang diserap lebih besar. Ini terjadi pada konfigurasi serpentine-paralel dan paralel-serpentine.

\section{KESIMPULAN}

Efesiensi kolektor meningkat dengan adanya modifikasi jenis material, serial konfigurasi dan dimensi pipa penyerap panas. Hal ini disebabkan oleh konduktivitas panas material yang berbeda, sehingga daya isolasi air panas dalam tandon stainless steel lebih baik dibandingkan dengan dari bahan fiberglass. Selanjutnya, peningkatan suhu air sirkulasi dari paralel ke serpentine menjadi lebih tinggi karena kecepatan fluida menjadi lambat pada model serpentine sebelum masuk ke tandon.

Penulis menyampaikan terima kasih kepada DP2M Pendidikan Tinggi Kementerian Pendidikan dan Kebudayaan $\mathrm{Rl}$ atas dana penelitian Hibah Bersaing, sehingga penulis dapat melaksanakan penelitian ini.

\section{DAFTAR PUSTAKA}

[1] Duffie, J.A., dan Beckman, W.A., 2006, "Solar Engineering of Thermal Processes," 3rd Ed., Hobokem, NJ: John Wiley \& Son.

[2] Handoyo, E.A., 2000, "Perbandingan Konfigurasi Pipa Paralel dan Serpentine pada Unjuk Kerja Kolektor Surya Plat Datar, diakses di Internet pada http://puslit.petra.ac.id/journals/mechanical

[3] Mustofa, Rahman Y.A., \& Muchsin, 2014 Rekayasa Kolektor Energi Surya Tipe Singe and Double Cover Glazing (SIDOCI) Dengan Pelat Datar dan Gelombang Sinusoidal, LPM UNTAD, Palu.

[4] Mustofa, Rahman Y.A., Muchsin \& Hatib R., 2013a, "A New Copper Tube Configuration of Solar Water Heating Collector: Single and Double", Proceeding of Engineering International Conference, Semarang, pp. 1-4, ISBN 97925-2784

[5] Mustofa, Rahman Y. A., Muchsin \& Nugraha R.C.G., 2013b, "Hybrid Plat Datar dan Gelombang Sinusoidal pada Kolektor Pemanas Air Surya", Prosiding Seminar 
Nasional Teknologi Industri I, Makassar, ISBN 978-602-14537-0-4, hal. 99-105.

[6] Supriadi (2010), Uji Performansi Kolektor Panas Surya Plat Datar dan Plat Gelombang Dengan Variasi Jarak Dua Kaca Penutup, Tugas Akhir, Jurusan Fisika FMIPA, UNS. 